\title{
Endoscopic Features of Upper Gastrointestinal Tract in Patients with Systemic Sclerosis Compared to the Healthy Control
}

\author{
Jun Won Park ${ }^{1}$, Jihye Kim², ${ }^{2,3}$ Eun Ae Kang ${ }^{3}$, Min Jung Kim ${ }^{1}$, Joo Sung Kim³ , Eun Bong Lee ${ }^{1}$ \\ ${ }^{1}$ Division of Rheumatology, Department of Internal Medicine, Seoul National University College of Medicine, ${ }^{2}$ Department of Internal Medicine, \\ CHA Gangnam Medical Center, CHA University School of Medicine, ${ }^{3}$ Department of Internal Medicine and Liver Research Institute, Seoul \\ National University College of Medicine, Seoul, Korea
}

\begin{abstract}
Objective. To characterize the endoscopic features of upper gastrointestinal tract in patients with systemic sclerosis (SSc) compared with those in the healthy controls. Methods. Data on esophagogastroduodenoscopy (EGD) in 180 patients with SSc (SSc group) were compared with that from the 181 age- and sex-matched healthy control who underwent EGD for routine check-up (control group). Clinical data of participants at the time of EGD (defined as baseline) were collected from electric medical record. Endoscopic findings were evaluated by two experts with blinded to their clinical features. Primary outcome of the study was prevalence of each endoscopic lesion between the two groups. Results. The mean \pm standard deviation age and disease duration in the SSc group at baseline were $55.3 \pm 11.8$ and $2.9 \pm 3.7$ years, respectively. Compared to the control group, SSc group more frequently showed reflux esophagitis $(32.8 \%$ vs. $9.4 \%, \mathrm{p}<0.001)$. In contrast, prevalence of atrophic gastritis was significantly lower in the SSc group ( $8.3 \%$ vs. $29.3 \%$, p < 0.001). This result was consistent in the multivariable analysis where patients' age and concomitant proton pump inhibitor use were adjusted. There was no case of gastric antral vascular ectasia (GAVE) in both groups. However, 29 (16.1\%) patients in SSc group showed a clinically significant anemia (hemoglobin $<10$ $\mathrm{mg} / \mathrm{dL}$ ), with none of the endoscopic features showed significant associations with the outcome. Conclusion. Patients with SSc showed significantly lower prevalence of atrophic gastritis. There was no case of GAVE, which suggests that clinical phenotype of the SSc could be different according to the ethnicity or geographic region. (J Rheum Dis 2019;26:66-73)
\end{abstract}

Key Words. Scleroderma, systemic, Endoscopy, Gastritis, Gastric antral vascular ectasia

\section{INTRODUCTION}

Systemic sclerosis (SSc) is a chronic autoimmune disease characterized by proliferative vascular lesions and fibrosis in skin and various internal organs [1]. Gastrointestinal tract is the second most commonly involved organ, present in approximately $75 \% \sim 90 \%$ of the SSc patients [2]. Gastrointestinal involvement is also the leading cause of morbidity and third most common cause of the mortality in SSc [3,4].

Among various parts of gastrointestinal tract, esophagus is the most commonly involved organ. Esophageal reflux is one of the most common manifestation in SSC and its pathophysiology and related complication had been thoroughly investigated [5,6]. In contrast, there has been only a few studies focused on the gastric involvement of SSc, despite the prevalent use of esophagogastroduodenoscopy (EGD). Previous studies suggested that the gastric involvement in patients with SSc includes severe gastrointestinal bleeding or iron-deficiency anemia due to gastric antral vascular ectasia (GAVE) $[7,8]$. It is an endoscopic finding characterized by dilated submucosal vessels which radiate from the pylorus to the antrum. The exact prevalence of GAVE remains uncertain and were

Received : November 24, 2018, Revised : November 29, 2018, Accepted : November 30, 2018

Corresponding to : Eun Bong Lee (D http://orcid.org/0000-0003-0703-1208

Division of Rheumatology, Department of Internal Medicine, Seoul National University College of Medicine, 101 Daehak-ro, Jongno-gu, Seoul 03080, Korea. E-mail : leb7616@snu.ac.kr

Copyright (c) 2019 by The Korean College of Rheumatology. All rights reserved.

This is a Open Access article, which permits unrestricted non-commerical use, distribution, and reproduction in any medium, provided the original work is properly cited. 
highly variable among studies (from approximately $1 \%$ to $22.3 \%$ ), suggesting that ethnicity and geographic region could influence on its pathophysiology [9-11]. However, there have been no studies which investigated the prevalence of GAVE in patients with SSc in Korea. Furthermore, endoscopic features of stomach other than GAVE in patients with SSc also remained unknown.

In the present study, therefore, we investigated the upper endoscopic findings of patients with SSc in South Korea and compared them with those from the matched healthy population.

\section{MATERIALS AND METHODS}

\section{Subjects}

This is a cross-sectional study using electric database of medical records of a tertiary referral center located in South Korea. We collected the endoscopic data performed in patients who were diagnosed with SSc between January 2004 and August 2017. All included patients fulfilled the 2013 American College of Rheumatology (ACR)/European League Against Rheumatism (EULAR) classification criteria for SSc at the time of diagnosis [12]. If a patient had multiple times of EGD, the data of the nearest date from the diagnosis was collected. The subtype of SSc was defined according to the previous report by LeRoy et al. [13]. Data on endoscopic examinations performed in the healthy population for the routine check-up in 2016 were used as the controls. In a total of 1,511 evaluations performed in this period, we selected the endoscopic data from age and sex-matched population using propensity score matching with a matching ratio of 1:1. Among them, one endoscopic data from a patient with SSc was excluded because of the limited evaluation due to severe esophageal stricture. Finally, one-hundred eighty patients with SSc (SSc group) and 181 general population (control group) were analyzed in this study.

The study was approved by the local Institutional Review Board (IRB no. 1708-092-878) and was conducted in accordance with the principles of the Declaration of Helsinki and Good Clinical Practice guidelines. Patient consent was waived by the IRB due to the retrospective character of the study.

\section{Clinical data}

Baseline date was defined as the date of endoscopic examination. Disease duration was defined as the time interval between the date of diagnosis of SSc and the base- line date. Demographic features, concomitant medications and other clinical and laboratory features at baseline were collected from patients' medical records. Data regarding the onset of Raynaud's phenomenon and non-Raynaud's phenomenon symptom were also collected. All included patients performed complete blood count $(\mathrm{CBC})$ test within one month from the baseline. Anemia was defined when hemoglobin level was less than $12 \mathrm{~g} / \mathrm{dL}$. If a baseline hemoglobin level less than $10 \mathrm{~g} / \mathrm{dL}$ (defined as a significant anemia), we collected data on additional evaluation for anemia such as serum ferritin, iron, total iron binding capacity (TIBC), folate and vitamin B12 within 6 months from baseline. Iron deficiency anemia (IDA) was defined when serum ferritin $<15 \mathrm{mg} / \mathrm{dL}$ and serum iron $<50 \mathrm{mcg} / \mathrm{dL}$. If a patient had normal or decreased level of TIBC, he or she was regarded as having anemia of chronic disease (ACD).

\section{Evaluation of endoscopic findings}

All endoscopic images were taken in accordance with specific guidelines for standardized image documentation in upper gastrointestinal endoscopy [14-16]. These guidelines recommend the acquisition of more than $8 \mathrm{im}$ ages of particular GI landmarks including 2 esophageal, 4 gastric, and 2 duodenal standard images. In the case of abnormal findings, additional complementary images were taken. Endoscopic images were managed and saved by picture archiving and communication systems (PACS) in real time with endoscopic evaluation. All endoscopic data in PACS were independently evaluated by two experienced gastroenterologists with blinded to all clinical data of the patients. Abnormal endoscopic findings were defined only when both readers give the same evaluation for the lesion.

Reflux esophagitis was defined as mucosal breaks of esophagus and was graded by Los Angeles classification of reflux esophagitis. Gastritis and intestinal metaplasia were diagnosed based on the characteristic endoscopic findings such as vascular pattern of gastric mucosa and nodular mucosal pattern, respectively. The diagnosis of GAVE was confirmed by characteristic endoscopic finding of erythematous, longitudinal stripes involving antrum and pylorus. Delayed gastric emptying, which can be a sign of gastroparesis, was considered present if food was remained in the stomach after the overnight fast before the examination.

Primary outcome of the study was prevalence of endoscopic lesions including GAVE between the two groups. 
Secondary outcomes included the prevalence of significant anemia and its associated clinical/endoscopic features.

\section{Statistical analysis}

Continuous variables were presented as mean \pm standard deviation $\pm \mathrm{SD}$. The prevalence of endoscopic lesions between the two groups were compared using Chi-square test. Binary logistic regression was used to investigate the effect of clinical factors associated with the endoscopic lesion. If a variable showed a relevant association $(\mathrm{p}<$ 0.1 ) with the outcome in the univariable model, it was included in the multivariable model as a covariate. If a covariate showed the completely separation of the outcome, Firth's penalized maximum likelihood was introduced to reduce the statistical bias [17]. All statistical analysis was performed using the R 3.3.1 (R Development Core Team, 2013; http://www.r-project.org). A p-value of $<0.05$ was considered statistically significant.

\section{RESULTS}

\section{Baseline clinical features of the patients}

Baseline characteristics of the patients were presented in Table 1. Briefly, mean \pm SD age in the SSc group was $53.3 \pm 11.8$ and $157(87.2 \%)$ patients were female. Eighty-nine (48.9\%) patients had diffuse subtype. Mean disease duration of the patients were $2.9 \pm 3.7$ years and $78.2 \%$ of the patients performed the esophagogastroduodenoscopy (EGD) within 5 years from the diagnosis of SSc. Most patients (123/179, 69.3\%) had at least one gastrointestinal symptom at baseline. Esophageal reflux (40.2\%), followed by early satiety $(25.0 \%)$ and dysphagia (24.4\%). In SSc group, 101 (56.1\%) patients received proton-pump inhibitor (PPI) at baseline whereas only 4 patients were treated with PPI in the control group for the treatment of gastroesophageal reflux disease (GERD).

\section{Prevalence of endoscopic abnormalities}

The reliability of endoscopic evaluation between the two readers was excellent in all endoscopic lesions and completely identical in case of peptic ulcer disease and GAVE (Supplementary Table 1). Prevalence of each endoscopic lesion between the two groups were presented in Table 2 . In the SSc group, reflux esophagitis was the most common endoscopic lesion, which was significantly more frequent than the control group ( $32.8 \%$ vs. $9.4 \%, \mathrm{p}<0.001)$.
High-grade esophagitis (defined as LA-C or D) was also frequently detected in the SSc group but not in the control group $(25.0 \%$ vs. $0.0 \%)$. Interestingly, in patients with SSc and reflux esophagitis, $44.8 \%(26 / 58)$ had no reflux symptoms at baseline. Prevalence of Barrett esophagus was also numerically higher in the SSc group $(1.7 \%$ vs. $0.0 \%, \mathrm{p}=0.081$ ).

Erosive and chronic atrophic gastritis were the two most common endoscopic lesions in the control group. They were detected in $21.0 \%$ and $29.3 \%$ in this group, respectively, but most patients had no related symptoms. In contrast, they were significantly less prevalent in the SSc

Table 1. Clinical features of the included patients with systemic sclerosis $(n=180)$

\begin{tabular}{|c|c|}
\hline Clinical feature & Value \\
\hline Age (yr) & $53.3 \pm 11.8$ \\
\hline Male sex & $23(12.8)$ \\
\hline Time from the onset of Raynaud phenomenon (yr) & $5.6 \pm 6.6$ \\
\hline $\begin{array}{l}\text { Time from the onset of non-Raynaud } \\
\text { phenomenon symptom (yr) }\end{array}$ & $3.4 \pm 4.0$ \\
\hline Disease duration $(y r),(n=179)$ & $2.9 \pm 3.7$ \\
\hline Disease duration less than 5 years $(n=179)$ & $140(77.8)$ \\
\hline Ever-smokers & $15(8.3)$ \\
\hline Diffuse subtype & $88(48.9)$ \\
\hline Limited subtype & $92(51.1)$ \\
\hline Anti-scl70 antibody positive $(n=171)$ & $72(48.0)$ \\
\hline Anti-centromere antibody positive $(n=171)$ & $38(25.3)$ \\
\hline Anti-U1RNP antibody positive $(n=154)$ & $23(16.9)$ \\
\hline Telangiectasia $(n=145)$ & $32(22.1)$ \\
\hline Interstitial lung disease & $110(61.1)$ \\
\hline \multicolumn{2}{|l|}{ GI manifestations } \\
\hline Dysphasia & $44(24.4)$ \\
\hline Reflux & $72(40.0)$ \\
\hline Early satiety & $45(25.0)$ \\
\hline Vomiting & $10(5.6)$ \\
\hline Diarrhea & $29(16.1)$ \\
\hline Constipation & $13(7.2)$ \\
\hline Abdominal pain & $26(14.4)$ \\
\hline Melena & $1(0.6)$ \\
\hline Anemia* & $73(40.6)$ \\
\hline 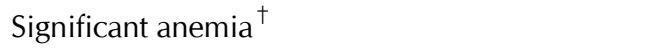 & $29(19.1)$ \\
\hline NSAID use at baseline $(n=179)$ & $27(15.1)$ \\
\hline Steroid use at baseline $(n=179)$ & $59(33.0)$ \\
\hline PPI use at baseline $(n=170)$ & $101(56.1)$ \\
\hline $\mathrm{ESR}(\mathrm{mm} / \mathrm{hr})$ & $34.0 \pm 26.1$ \\
\hline
\end{tabular}

Values are presented as mean \pm standard deviation or number (\%). GI: gastrointestinal, PPI: Proton-pump inhibitor, ESR: erythrocyte sedimentation rate. *Anemia was defined as the hemoglobin level less than $12 \mathrm{~g} / \mathrm{dL} .{ }^{\dagger}$ Significant anemia was defined as the hemoglobin level less than $10 \mathrm{~g} / \mathrm{dL}$. 
Table 2. Prevalence of endoscopic lesion between the two groups

\begin{tabular}{|c|c|c|c|}
\hline Endoscopic lesions & Control group $(n=181)$ & SSc group $(n=180)$ & p-value \\
\hline Reflux esophagitis & $17(9.4)$ & $59(32.8)$ & $<0.001$ \\
\hline Low grade (LA-A or B) & $17(100.0)$ & $45(75.0)$ & \\
\hline High grade (LA-C or D) & $0(0.0)$ & $15(25.0)$ & \\
\hline Barrett esophagus & $0(0.0)$ & $3(1.7)$ & 0.081 \\
\hline Esophageal stricture & $0(0.0)$ & $3(1.7)$ & 0.081 \\
\hline Chronic superficial gastritis & $42(23.2)$ & $31(17.2)$ & 0.157 \\
\hline Erosive gastritis & $38(21.0)$ & $21(11.7)$ & 0.017 \\
\hline Atrophic gastritis & $53(29.3)$ & $15(8.3)$ & $<0.001$ \\
\hline Intestinal metaplasia & $8(4.4)$ & $2(1.1)$ & 0.055 \\
\hline GAVE & $0(0.0)$ & $0(0.0)$ & NA \\
\hline Gastric ulcer & $0(0.0)$ & $4(2.2)$ & 0.044 \\
\hline Duodenal ulcer & $3(1.7)$ & $5(2.8)$ & 0.470 \\
\hline Hyperplastic polyp & $5(2.8)$ & $9(5.0)$ & 0.271 \\
\hline Adenomatous polyp & $1(0.6)$ & $2(1.1)$ & 0.559 \\
\hline Early gastric cancer & $1(0.6)$ & $1(0.6)$ & 0.997 \\
\hline
\end{tabular}

Values are presented as number (\%). SSc: systemic sclerosis, LA: Los Angeles classification criteria for reflux esophagitis, GAVE: gastric antral vascular ectasia, NA: non-applicable.

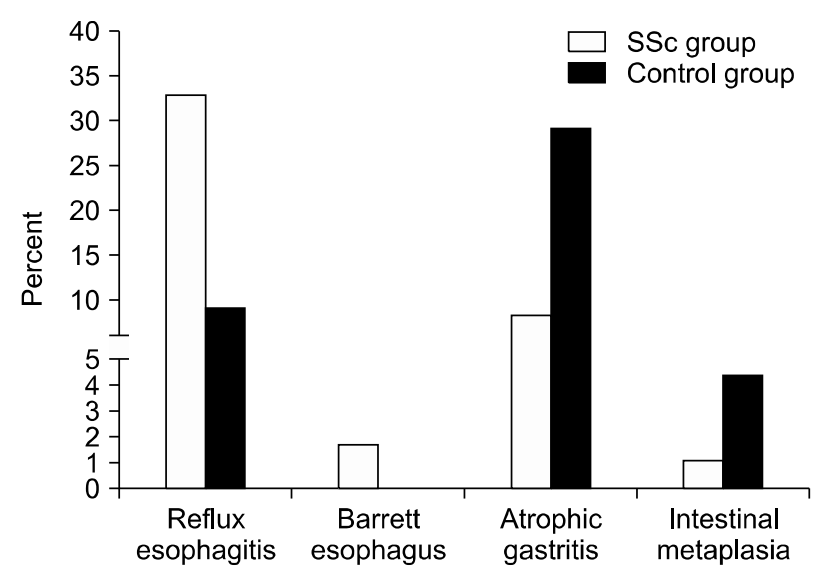

Figure 1. Prevalence of reflux esophagitis, atrophic gastritis and their advanced lesions between the systemic sclerosis (SSc) and the control groups.

group. Of note, atrophic gastritis was present only in 17 (9.3\%) patients in the SSc group (Figure 1). This result was not changed in the multivariable analysis where patient's age and concomitant PPI use were included as covariates (adjusted odds ratio [OR] $=0.17,95 \%$ confidence interval [CI] 0.07 to $0.38, \mathrm{p}<0.001$ ) (Table 3). Intestinal metaplasia was also less common in the SSc group although it was not statistically significant (1.1\% vs. $4.4 \%$, $\mathrm{p}=0.055)$. Suspicious early gastric cancer was incidentally found in 2 patients (one in each group) and biopsy in this lesion confirmed the diagnosis. There was no GAVE in both groups.

When patients with SSc were stratified according to the disease duration, Barrett esophagus, esophageal stricture and retained food in stomach were more frequently shown in patients with longer disease duration $(>5$ years). Prevalence of all endoscopic lesions was not different according to the subtype of SSc.

\section{Association between endoscopic lesion and anemia}

At the baseline, $73(40.6 \%)$ patients in the SSc group had an anemia and 29 (16.1\%) of them showed a significant anemia. Among them, IDA was detected in 14 (48.3\%) patients and 19 (65.5\%) patients showed the features of ACD. Patients with significant anemia were all female, were older $(58.9 \pm 12.3$ vs. $52.2 \pm 11.5$ years, $\mathrm{p}=0.005)$ and showed higher Erythrocyte sedimentation rate (ESR) level $(58.9 \pm 31.9$ vs. $29.3 \pm 21.9 \mathrm{~mm} / \mathrm{hr}, \mathrm{p}<$ $0.001)$ than the other patients. In addition, prevalence of pulmonary hypertension was also significantly higher in this subgroup ( $40.0 \%$ vs. $19.1 \%, \mathrm{p}=0.022$ ). Multivariable analysis showed that only high ESR level at baseline was significantly associated with the outcome (adjusted $\mathrm{OR}=1.04,95 \%$ CI 1.02 to $1.06, \mathrm{p}<0.001$ ) (Table 4). By contrast, no specific endoscopic lesion was associated with the presence of significant anemia. Correlation coefficient between ESR and hemoglobin levels in this analysis $(r=-0.524, p<0.001)$ was prominently greater than previously reported value (Supplementary Figure 1) [18].

\section{Sensitivity analysis}

Because lower prevalence of atrophic gastritis in the SSc 
Jun Won Park et al.

Table 3. Clinical features associated with atrophic gastritis on baseline EGD

\begin{tabular}{|c|c|c|c|c|}
\hline \multirow{2}{*}{ Variable } & \multicolumn{2}{|c|}{ Univariable analysis } & \multicolumn{2}{|c|}{ Multivariable analysis* } \\
\hline & OR $(95 \% \mathrm{Cl})$ & p-value & Adjusted OR (95\% Cl) & p-value \\
\hline Age & 1.06 (1.03 to 1.09$)$ & $<0.001$ & 1.06 (1.04 to 1.09$)$ & $<0.001$ \\
\hline Male sex & 1.05 (0.48 to 2.31$)$ & 0.892 & 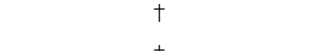 & \\
\hline Disease duration & 0.95 (0.81 to 1.12$)$ & 0.532 & $\dagger$ & \\
\hline Ever-smokers & $0.31(0.27$ to 2.44$)$ & 0.707 & ${ }^{\dagger}$ & \\
\hline PPI use at baseline & 0.35 (0.17 to 0.72$)$ & $<0.001$ & 1.23 (0.46 to 3.26$)$ & 0.681 \\
\hline Systemic sclerosis (vs. normal control) & 0.22 (0.12 to 0.410 & $<0.001$ & 0.17 (0.07 to 0.38$)$ & $<0.001$ \\
\hline
\end{tabular}

EGD: esophagogastroduodenoscopy, OR: odds ratio, $\mathrm{Cl}$ : confidence interval, PPI: proton pump inhibitor. ${ }^{*}$ Clinical factors with a significant association $(p<0.1)$ were included in the multivariable model. ${ }^{\dagger}$ Does not included in the multivariable model as a covariate.

Table 4. Clinical features associated with significant anemia at baseline

\begin{tabular}{|c|c|c|c|c|}
\hline \multirow{2}{*}{ Variable } & \multicolumn{2}{|c|}{ Univariable analysis } & \multicolumn{2}{|c|}{ Multivariable analysis* ${ }^{\ddagger}$} \\
\hline & OR $(95 \% \mathrm{Cl})$ & p-value & Adjusted OR (95\% Cl) & p-value \\
\hline Age & 1.05 (1.02 to 1.09$)$ & 0.006 & 1.02 (0.98 to 1.07$)$ & 0.351 \\
\hline Female sex ${ }^{\ddagger}$ & $10.78(1.42$ to $1,384.20)$ & 0.014 & 5.59 (0.531 to 781.39$)$ & 0.179 \\
\hline Disease duration & 1.09 (0.99 to 1.20$)$ & 0.098 & 1.11 (0.98 to 1.26$)$ & 0.084 \\
\hline Ever-smokers $^{\ddagger}$ & 0.15 (0.001 to 1.17$)$ & 0.076 & $0.76(0.01$ to 11.69$)$ & 0.866 \\
\hline ESR & 1.04 (1.02 to 1.06$)$ & $<0.001$ & 1.04 (1.02 to 1.06$)$ & $<0.001$ \\
\hline PPI use at baseline & $0.58(0.26$ to 1.30$)$ & 0.184 & † & \\
\hline Reflux esophagitis & $1.10(0.47$ to 2.53$)$ & 0.831 & $\dagger$ & \\
\hline Barrett esophagus & $2.66(0.23$ to 30.35$)$ & 0.431 & $\dagger$ & \\
\hline Chronic superficial gastritis & $0.31(0.07$ to 1.39$)$ & 0.126 & $\dagger$ & \\
\hline Erosive gastritis & $0.85(0.23$ to 3.11$)$ & 0.809 & $\dagger$ & \\
\hline Atrophic gastritis & $0.79(0.17$ to 3.69$)$ & 0.760 & $\dagger$ & \\
\hline Intestinal metaplasia $^{\ddagger}$ & 1.01 (0.01 to 12.88$)$ & 0.993 & $\dagger$ & \\
\hline Retained food in stomach & 2.66 (0.23 to 30.35$)$ & 0.431 & $\dagger$ & \\
\hline${\text { Gastric } \text { ulcer }^{\ddagger}}^{\ddagger}$ & $0.56(0.004$ to 5.43$)$ & 0.673 & + & \\
\hline Duodenal ulcer ${ }^{\ddagger}$ & 0.45 (0.003 to 4.16$)$ & 0.553 & $\dagger$ & \\
\hline
\end{tabular}

OR: odds ratio, Cl: confidence interval, ESR: erythrocyte sedimentation rate, PPI: proton pump inhibitor. ${ }^{*}$ Clinical factors with a significant association $(p<0.1)$ were included in the multivariable model. ${ }^{\dagger}$ Does not included in the multivariable model as a covariate. ${ }^{\dagger}$ Firth penalized maximum likelihood was used due to complete separation of outcome.

group could be attributed to therapeutic effect of PPI, we repeated the same comparison after excluding those receiving this agent at baseline. The result was consistent with that performed in the whole-population; the prevalence of atrophic gastritis was $7.6 \%$ in the SSc group compared with $29.9 \%$ in the control group $(\mathrm{p}<0.001)$ (Supplementary Table 2). In addition, it is possible that lower resolution of PACS image taken in the early 2000s could decrease the detection rate of atrophic gastritis and intestinal metaplasia, we compared the prevalence of endoscopic lesions between the two groups after excluding 22 EGD PACS data taken before the 2007. In this sensitivity analysis, SSc group showed significantly lower prev- alence of atrophic gastritis than the control group (Supplementary Table 3).

\section{DISCUSSION}

Gastrointestinal involvement commonly occurs in patients with SSc, resulting in various symptoms and impairment of quality of life [19]. Although SSc can involve the any site in gastrointestinal tract, there have been few studies that investigated its gastric involvement. Furthermore, prevalence of peptic ulcer disease and gastric cancer in South Korea is significantly higher than that in the western countries, which suggests that clinical features of 
stomach involvement in SSc could be different according to the ethnic or environmental factors [20-22]. To our knowledge, this is the first study performed in Asian countries that investigated the endoscopic features of upper gastrointestinal tract in patients with SSc compared with those in general population.

In accordance with the previous studies, patients with SSc showed significantly higher prevalence of reflux esophagitis than healthy controls. However, nearly half of them $(44.8 \%)$ showed no reflux symptoms, which emphasizes the importance of meticulous surveillance of esophageal involvement even in patients without reflux symptom [23,24]. In this study, Barrett esophagus was detected in only 3 (1.7\%) patients and all of them had longer disease duration. Although the preventive effect of PPI on esophageal adenocarcinoma in patients with SSc is still uncertain, many previous reports suggested that proper management of reflux esophagitis using PPI could reduce its progression to Barrett esophagus $[25,26]$.

It is very interesting that the prevalence of atrophic gastritis, known precancerous lesion of gastric adenocarcinoma, was significantly lower in the SSc group. Furthermore, this result was not changed after adjustment for the PPI use or after excluding PPI-users. This result suggests that patients with SSc could have some protective factors for gastric atrophy and potentially, gastric adenocarcinoma. There has been few studies which investigated the prevalence of atrophic gastritis in patients with autoimmune diseases. However, Ebert and Hagspiel [27] reported that $62.5 \%$ of gastric biopsy specimens from the patients with rheumatoid arthritis showed chronic atrophic gastritis. This suggests that the less frequent atrophic gastritis could be a characteristic endoscopic feature of SSc rather than general finding in the autoimmune diseases. It was also supported by some cohort studies which reported that SSc patients had a lower incidence of gastrointestinal cancer as compared with the general population [28-30]. In addition, prevalence of atrophic gastritis in the control group was also comparable to that in the large, multicenter study performed in South Korea [31]. Therefore, it is less likely that our result could be attributed to the lower detection rate of the lesion. Contrary to our study, Thonhofer et al. [32] reported the endoscopic gastritis was present in $92 \%$ (31\% erosive gastritis) of patients with early SSc although the number of included patients in this study was so small and prevalence of atrophic gastritis was not clarified. Furthermore, the underlying mechanism to explain this phenomenon is also uncertain. Therefore, the result from this study should be confirmed in future large-scale study to broaden our understanding the relationship between SSc and pathogenesis of gastric adenocarcinoma.

It is also interesting that there was no case of GAVE in this study. Most previous studies regarding a gastric involvement of SSc have focused on the GAVE, which is known to be an important cause of chronic bleeding and iron deficiency anemia in SSc. However, most of the previous studies regarding GAVE were from European or American countries whereas there have been only two case reports of GAVE which occurred in Asian patients with SSc $[33,34]$. This result suggests that there could be significant difference in clinical phenotype of SSc according to the ethnicity or geographic region. Of note, $16.1 \%$ of the patients showed significant anemia at baseline without evidence of gastrointestinal bleeding and about half of them showed laboratory features of iron deficiency anemia. There have been few studies which investigated the cause of iron deficiency in SSc other than GAVE but decreased iron absorption due to gastrointestinal involvement of SSc, occult bleeding in small intestine or frequent use of PPI might play a role [35]. Interestingly, high ESR level was closely associated with the significant anemia. Although ESR is normally elevated with decreasing hemoglobin level, the degree of correlation was greater than previously reported one [18]. This suggests that inflammation could be an important factor in the pathogenesis of anemia in patients with SSc.

This study has some limitations to be considered. First, since it is a cross-sectional study, the result could be influenced by previous medications and co-morbidities. Although we thoroughly reviewed the participants' medical records, unmeasured confounders such as use of over-the-counter medicine could not be fully adjusted in this study. Second, although the diagnosis of gastritis was performed under the evaluation of two expert gastroenterologists to minimize the bias, gold-standard of diagnosis in gastritis is a pathological evaluation. Furthermore, evaluation for $\mathrm{H}$. pylori infection, an important pathogenesis of atrophic gastritis, was not addressed in this study because rapid urease test in patients with gastritis is not routinely performed in South Korea. Finally, because the data in this study were collected from a single-center registry, this result should be replicated in larger, multicenter study for generalizability. 


\section{CONCLUSION}

In conclusion, we show here that patient with SSc in South Korea showed significantly higher prevalence of reflux esophagitis but lower prevalence of atrophic gastritis than healthy controls. We also showed that anemia and iron deficiency was relatively common features despite the absence of GAVE. Although this result should be confirmed in future studies, it can be an important basis to characterize the clinical features of SSc patients in South Korea.

\section{ACKNOWLEDGMENTS}

This research was supported by a grant of the Korea Health Technology R\&D Project through the Korea Health Industry Development Institute (KHIDI), funded by the Ministry of Health \& Welfare, Republic of Korea (grant number: HI17C1234).

\section{CONFLICT OF INTEREST}

No potential conflict of interest relevant to this article was reported.

\section{SUPPLEMENTARY DATA}

Supplementary data can be found with this article online at https://doi.org/10.4078/jrd.2019.26.1.66.

\section{REFERENCES}

1. Denton CP, Khanna D. Systemic sclerosis. Lancet 2017;390: 1685-99.

2. Forbes A, Marie I. Gastrointestinal complications: the most frequent internal complications of systemic sclerosis. Rheumatology (Oxford) 2009;48 Suppl 3:iii36-9.

3. Altman RD, Medsger TA Jr, Bloch DA, Michel BA. Predictors of survival in systemic sclerosis (scleroderma). Arthritis Rheum 1991;34:403-13.

4. Hunzelmann N, Genth E, Krieg T, Lehmacher W, Melchers I, Meurer M, et al. The registry of the German network for systemic scleroderma: frequency of disease subsets and patterns of organ involvement. Rheumatology (Oxford) 2008;47:1185-92.

5. Alastal Y, Hammad TA, Renno A, Khalil B, Pierre J, Kwaah $B$, et al. Gastrointestinal manifestations associated with systemic sclerosis: results from the nationwide inpatient sample. Ann Gastroenterol 2017;30:498-503.

6. McFarlane IM, Bhamra MS, Kreps A, Iqbal S, Al-Ani F, Saladini-Aponte C, et al. Gastrointestinal manifestations of systemic sclerosis. Rheumatology (Sunnyvale) 2018;8. pii:
235.

7. Savarino E, Furnari M, de Bortoli N, Martinucci I, Bodini G, Ghio M, et al. Gastrointestinal involvement in systemic sclerosis. Presse Med 2014;43:e279-91.

8. Watson M, Hally RJ, McCue PA, Varga J, Jiménez SA. Gastric antral vascular ectasia (watermelon stomach) in patients with systemic sclerosis. Arthritis Rheum 1996;39: 341-6.

9. Ghrénassia E, Avouac J, Khanna D, Derk CT, Distler O, Suliman YA, et al. Prevalence, correlates and outcomes of gastric antral vascular ectasia in systemic sclerosis: a EUSTAR case-control study. J Rheumatol 2014;41:99-105.

10. Hung EW, Mayes MD, Sharif R, Assassi S, Machicao VI, Hosing C, et al. Gastric antral vascular ectasia and its clinical correlates in patients with early diffuse systemic sclerosis in the SCOT trial. J Rheumatol 2013;40:455-60.

11. Marie I, Levesque H, Ducrotté P, Denis P, Hellot MF, Benichou J, et al. Gastric involvement in systemic sclerosis: a prospective study. Am J Gastroenterol 2001;96:77-83.

12. van den Hoogen F, Khanna D, Fransen J, Johnson SR, Baron M, Tyndall A, et al. 2013 classification criteria for systemic sclerosis: an American college of rheumatology/European league against rheumatism collaborative initiative. Ann Rheum Dis 2013;72:1747-55.

13. LeRoy EC, Black C, Fleischmajer R, Jablonska S, Krieg T, Medsger TA Jr, et al. Scleroderma (systemic sclerosis): classification, subsets and pathogenesis. J Rheumatol 1988;15: 202-5.

14. Rey JF, Lambert R; ESGE Quality Assurance Committee. ESGE recommendations for quality control in gastrointestinal endoscopy: guidelines for image documentation in upper and lower GI endoscopy. Endoscopy 2001;33: 901-3.

15. Aabakken L, Barkun AN, Cotton PB, Fedorov E, Fujino MA, Ivanova $\mathrm{E}$, et al. Standardized endoscopic reporting. J Gastroenterol Hepatol 2014;29:234-40.

16. Marques S, Bispo M, Pimentel-Nunes P, Chagas C, Dinis-Ribeiro $\mathrm{M}$. Image documentation in gastrointestinal endoscopy: review of recommendations. GE Port J Gastroenterol 2017;24:269-74.

17. Heinze G, Schemper M. A solution to the problem of separation in logistic regression. Stat Med 2002;21:2409-19.

18. Kanfer EJ, Nicol BA. Haemoglobin concentration and erythrocyte sedimentation rate in primary care patients. J R Soc Med 1997;90:16-8.

19. Tiev KP, Cabane J. Digestive tract involvement in systemic sclerosis. Autoimmun Rev 2011;11:68-73.

20. Sung JJ, Kuipers EJ, El-Serag HB. Systematic review: the global incidence and prevalence of peptic ulcer disease. Aliment Pharmacol Ther 2009;29:938-46.

21. Kim HS, Baik SJ, Kim KH, Oh CR, Lee JH, Jo WJ, et al. Prevalence of and risk factors for gastrointestinal diseases in Korean Americans and native Koreans undergoing screening endoscopy. Gut Liver 2013;7:539-45.

22. Lee HJ, Yang HK, Ahn YO. Gastric cancer in Korea. Gastric Cancer 2002;5:177-82.

23. Ntoumazios SK, Voulgari PV, Potsis K, Koutis E, Tsifetaki $\mathrm{N}$, Assimakopoulos DA. Esophageal involvement in scleroderma: gastroesophageal reflux, the common problem. Semin Arthritis Rheum 2006;36:173-81.

24. Denaxas K, Ladas SD, Karamanolis GP. Evaluation and 
management of esophageal manifestations in systemic sclerosis. Ann Gastroenterol 2018;31:165-70.

25. Triadafilopoulos G. Proton pump inhibitors for Barrett's oesophagus. Gut 2000;46:144-6.

26. Kahrilas PJ. Gastroesophageal reflux disease. JAMA 1996; 276:983-8.

27. Ebert EC, Hagspiel KD. Gastrointestinal and hepatic manifestations of rheumatoid arthritis. Dig Dis Sci 2011;56: 295-302.

28. Kuo CF, Luo SF, Yu KH, Chou IJ, Tseng WY, Chang HC, et al. Cancer risk among patients with systemic sclerosis: a nationwide population study in Taiwan. Scand J Rheumatol 2012;41:44-9.

29. Kang KY, Yim HW, Kim IJ, Yoon JU, Ju JH, Kim HY, et al. Incidence of cancer among patients with systemic sclerosis in Korea: results from a single centre. Scand J Rheumatol 2009;38:299-303.

30. Hashimoto A, Arinuma Y, Nagai T, Tanaka S, Matsui T, Tohma S, et al. Incidence and the risk factor of malignancy in Japanese patients with systemic sclerosis. Intern Med
2012;51:1683-8.

31. Joo YE, Park HK, Myung DS, Baik GH, Shin JE, Seo GS, et al. Prevalence and risk factors of atrophic gastritis and intestinal metaplasia: a nationwide multicenter prospective study in Korea. Gut Liver 2013;7:303-10.

32. Thonhofer R, Siegel C, Trummer M, Graninger W. Early endoscopy in systemic sclerosis without gastrointestinal symptoms. Rheumatol Int 2012;32:165-8.

33. Shibukawa G, Irisawa A, Sakamoto N, Takagi T, Wakatsuki $\mathrm{T}$, Imamura $\mathrm{H}$, et al. Gastric antral vascular ectasia (GAVE) associated with systemic sclerosis: relapse after endoscopic treatment by argon plasma coagulation. Intern Med 2007;46:279-83.

34. Yamamoto M, Takahashi H, Akaike J, Suzuki C, Naishiro Y, Yamamoto H, et al. Gastric antral vascular ectasia (GAVE) associated with systemic sclerosis. Scand J Rheumatol 2008;37:315-6.

35. McColl KE. Effect of proton pump inhibitors on vitamins and iron. Am J Gastroenterol 2009;104 Suppl 2:S5-9. 
pISSN: 2093-940X, elSSN: 2233-4718

Journal of Rheumatic Diseases Vol. 26, No. 1, January, 2019

https://doi.org/10.4078/jrd.2019.26.1.66

Supplementary Table 1. Reliability of endoscopic evaluation between the two readers

\begin{tabular}{lc}
\hline \multicolumn{1}{c}{ Endoscopic lesions } & Kappa $(95 \% \mathrm{Cl})$ \\
\hline Reflux esophagitis & $0.92(0.87$ to 1.00$)$ \\
Barrett esophagus & $0.66(0.30$ to 1.00$)$ \\
Esophageal stricture & $0.80(0.52$ to 1.00$)$ \\
Chronic superficial gastritis & $0.92(0.87$ to 0.97$)$ \\
Erosive gastritis & $0.96(0.92$ to 1.00$)$ \\
Atrophic gastritis & $0.97(0.94$ to 1.00$)$ \\
Intestinal metaplasia & $0.87(0.71$ to 1.00$)$ \\
GAVE & 1.00 \\
Gastric ulcer & 1.00 \\
Duodenal ulcer & 1.00 \\
Hyperplastic polyp & $0.96(0.89$ to 1.00$)$ \\
Adenomatous polyp & $0.75(0.41$ to 1.00$)$ \\
Early gastric cancer & 1.00 \\
\hline
\end{tabular}

$\mathrm{Cl}$ : confidence interval, GAVE: gastric antral vascular ectasia. 
Jun Won Park et al.

Supplementary Table 2. Prevalence of endoscopic lesion between the two groups in the subgroup of the patients without PPI

\begin{tabular}{lccc}
\hline \hline \multicolumn{1}{c}{ Endoscopic lesions } & Control group $(\mathrm{n}=174)$ & SSc group $(\mathrm{n}=79)$ & $\mathrm{p}$-value \\
\hline Reflux esophagitis & $16(9.2)$ & $18(22.8)$ & 0.003 \\
Low grade (LA-A or B) & $16(100.0)$ & $11(51.1)$ & \\
High grade (LA-C or D) & $0(0.0)$ & $7(38.9)$ & 0.137 \\
Barrett esophagus & $0(0.0)$ & $3(1.3)$ & 0.010 \\
Esophageal stricture & $0(0.0)$ & $17(21.5)$ & 0.795 \\
Chronic superficial gastritis & $40(23.0)$ & $8(10.1)$ & 0.025 \\
Erosive gastritis & $38(21.8)$ & $6(7.6)$ & $<0.001$ \\
Atrophic gastritis & $52(29.9)$ & $1(1.3)$ & 0.185 \\
Intestinal metaplasia & $8(4.6)$ & $0(0.0)$ & $\mathrm{NA}$ \\
GAVE & $0(0.0)$ & $1(1.3)$ & 0.137 \\
Gastric ulcer & $0(0.0)$ & $3(3.8)$ & $1(1.3)$ \\
Duodenal ulcer & $3(1.7)$ & $2(2.5)$ & 0.315 \\
Hyperplastic polyp & $5(2.9)$ & $0(0.0)$ & 0.436 \\
Adenomatous polyp & $1(0.6)$ & 0.183 \\
Early gastric cancer & $1(0.7)$ & 0.500 \\
\hline
\end{tabular}

Values are presented as number (\%). PPI: proton pump inhibitor, SSc: systemic sclerosis, LA: Los Angeles classification criteria for reflux esophagitis, GAVE: gastric antral vascular ectasia, NA: non-applicable. 


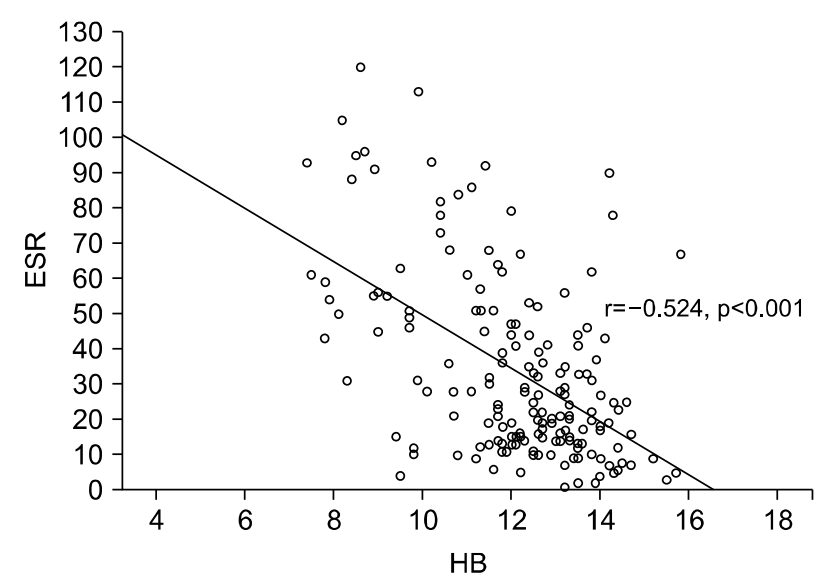

Supplementary Figure 1. Scatter plot indicating the degree of relationship between the ESR and hemoglobin levels. ESR: erythrocyte sedimentation rate, HB: hemoglobin. 
Jun Won Park et al.

Supplementary Table 3. Prevalence of endoscopic lesion between the two groups after excluding the PACS data with low resolution which was taken before 2007

\begin{tabular}{ccrr}
\hline \hline Endoscopic lesions & Control group $(\mathrm{n}=181)$ & SSc group $(\mathrm{n}=158)$ & $\mathrm{p}$-value \\
\hline Atrophic gastritis & $53(29.3)$ & $15(9.3)$ & $<0.001$ \\
Intestinal metaplasia & $8(4.4)$ & $2(1.3)$ & 0.087 \\
\hline
\end{tabular}

Values are presented as number (\%). PACS: picture archiving and communication system, SSc: systemic sclerosis. 